\title{
EQUILÍBRIO DE BAIXO NÍVEL: REVISÃO BIBLIOMÉTRICA
}

\section{REVISÃO BIBLIOMÉTRICA}

LEAL, Cícero Pereira1, CARVALHO, Rogério Galvão de², NASCIMENTO, José Antônio Rodrigues do ${ }^{3}$, FEIO, Kleydson Jurandir Gonçalves ${ }^{4}$

LEAL, Cícero Pereira. Et al. Equilíbrio de baixo nível: revisão bibliométrica. Revista Científica Multidisciplinar Núcleo do Conhecimento. Ano 06, Ed. 08, Vol. 03, pp. 171-187. Agosto de 2021. ISSN: 2448-0959, Link de acesso: https://www.nucleodoconhecimento.com.br/ciencias-sociais/baixo-nivel, $\quad$ DOI: 10.32749/nucleodoconhecimento.com.br/ciencias-sociais/baixo-nivel

\section{RESUMO}

O objetivo deste trabalho foi aferir a evolução dos estudos sobre o equilíbrio de baixo nível (EBN) nos últimos 75 anos (de 1945 a 2020) em revistas especializadas, por meio de identificar autores, os artigos e revistas mais citados durante o referido período. A armadilha de equilíbrio de baixo nível é um conceito em economia desenvolvido por Richard R. Nelson, no qual, em baixos níveis de renda per capita, as pessoas são pobres demais para economizar e investir, e esse baixo nível de investimento, resulta em taxa de crescimento menor na economia e na renda nacional. Quando a renda per capita se eleva acima de um certo nível mínimo, uma

\footnotetext{
${ }^{1}$ Doutorando em Ciências Sociais - Unisinos; Mestre em Gestão Econômica do Meio-Ambiente - Universidade de Brasília - UnB; Graduado em Economia - UnB.

${ }^{2}$ Doutorado em andamento em Ciências Empresariais e Sociais - Universidad de Ciencias Empresariales y Sociales, UCES, Argentina; Mestrado em Economia - Universidade Católica de Brasília (Conceito CAPES 6), UCB/DF, Brasil; Especialização em Especialização em Direito Público - Centro Universitário Estácio Brasília, Estácio Brasília, Brasil; Graduado em Economia - Centro Universitário de Brasília, UniCEUB, Brasil.

${ }^{3}$ Doutorando em Ciências Sociais - Unisinos; Mestre em Economia - UnB; Especialista em Administração Financeira - ICAT Instituto de Cooperação e Assistência Técnica; Graduado em Administração de Empresas AEUDF Associação de Ensino Unificado do DF.

${ }^{4}$ Mestre em Economia - UnB; Especialista em Finanças Públicas - Universidade Gama Filho - UGF; Especialista em Logística Reversa - Faculdade Grande Fortaleza - FGF; Graduado em Economia - Universidade Federal do Pará - UFPa. Bacharel em Administração - Faculdade Unibrasília.
}

RC: 94054

Disponível em: https://www.nucleodoconhecimento.com.br/ciencias-sociais/baixo- 
proporção crescente da renda será economizada e investida, o que poderá levar a uma maior taxa de crescimento da renda. Do contrário, haverá baixo crescimento da economia e precarização da produção, devido ao desequilíbrio econômicofinanceiro, bem como a falta de acesso da sociedade à bens e serviços. A metodologia utilizada foi a pesquisa bibliográfica de caráter exploratório, utilizando o enfoque meta-analítico. O referido método combina bases de dados, para dessa forma apresentar um aporte de material válido. O enfoque meta-analítico permite a identificação dos autores, artigos e revistas, assim como, viabiliza a realização da análise das técnicas estatísticas das amostras, linhas mais pesquisadas e principais abordagens feitas nos trabalhos publicados. Ao seguir os sete passos do método meta-analítico foi constatado que nas duas primeiras décadas do século XXI o tema deixou de ser pesquisado, todavia 07 (sete) países se interessam pelo tema, haja vista que ele foi abordado em vários campos de pesquisa como saúde, agricultura, mercado de trabalho, química e outros.

Palavras chaves: Equilíbrio de Baixo Nível, Enfoque Meta-Analítico, Bibliometria, Fator de Impacto.

\section{INTRODUÇÃO}

O objetivo deste trabalho é mensurar o estudo do equilíbrio de Baixo Nível (EBN) nos últimos 75 anos, em revistas especializadas, quer dizer, o quanto este tema foi abordado em trabalhos acadêmicos durante o período de 1945 a 2020. Tendo em vista que baixos níveis de renda per capta afetam substancialmente a formação de poupança e investimento tanto em países desenvolvidos como em países em desenvolvimento. $E$ isso pode afetar sobremaneira o crescimento econômico geral de uma economia e, por conseguinte, a formação da renda nacional. Como esta pesquisa trata-se de uma bibliometria, a pesquisa bibliográfica utilizada tem um caráter exploratório por meio do enfoque meta-analítico, tendo em vista que esta metodologia utiliza o critério de impacto de revistas e artigos para otimizar a seleção

RC: 94054

Disponível em: https://www.nucleodoconhecimento.com.br/ciencias-sociais/baixonivel 
do material que vai compor a pesquisa. A metodologia será realizada em 7 (sete) etapas que serão apresentadas durante a realização do presente trabalho. Os objetivos específicos são: a) avaliar a evolução das publicações sobre o presente tema durante o período de 1945 a 2020; b) averiguar os autores, os artigos e revistas mais citados durante o período supracitado.

Em um estudo realizado por Spiller e Savedoff (1999), para alguns países da América Latina, observou-se que os governos apresentam tendência para fixar preços abaixo do equilíbrio financeiro para o setor de abastecimento de água. Percebeu-se que isto provoca um desequilíbrio econômico-financeiro para as empresas públicas e privadas no que tange a oferta dos seus respectivos serviços. Com essa política de preços baixos as empresas não realizam investimentos e a receita é comprometida para pagamento de salários, inviabilizando a expansão e qualidades dos serviços. Quando o sistema é operado por empresa pública, os investimentos do setor supracitado ficam condicionados a repasses orçamentários do governo central, ou seja, a empresa pública precisa de auxílio para arcar com os seus compromissos financeiros.

De acordo com Spiller e Savedoff (1999) o resultado é a ineficiência das empresas, serviços de baixa qualidade e falta de expansão para novos consumidores. Com esse modelo de produção ineficiente e sem o suporte político, cria-se um "oportunismo" no qual o governo conserva os preços baixos, provocando um modelo vicioso, gerando um "Equilíbrio de Baixo Nível" (EBN). O objetivo do modelo de Spiller e Savedoff (1999, p. 2) e os estudos de Farias, Nogueira e Mueller (2005) é avaliar o equilíbrio financeiro das empresas prestadoras de bens e serviços de saneamento básico, bem como os impactos decorrentes deste desequilíbrio. Ao longo desse período, o país experimentou racionamento de água e não avançou na difusão dos serviços de coleta e tratamento de esgoto na velocidade planejada. Como resultado os salários pagos, aos trabalhadores do referido setor, são muito baixos e isso pode comprometer o crescimento da economia. Por isso o objetivo do

RC: 94054

Disponível em: https://www.nucleodoconhecimento.com.br/ciencias-sociais/baixo- 
presente trabalho é mensurar e analisar a evolução dos estudos sobre o equilíbrio de baixo nível nos últimos 75 anos (de 1945 a 2020) em revistas especializadas considerando os autores e artigos mais publicados no referido período. Para isso este tralhado está organizado da seguinte maneira: (a) a primeira parte, que é esta introdução; (b) a segunda parte, que é a revisão bibliográfica; (c) a terceira parte, que é são os métodos utilizados para realizar esta pesquisa; (d) a quarta parte, que é a análise e a apresentação dos dados da pesquisa; (d) e finalmente a quinta e última parte que é a conclusão da presente pesquisa.

\section{REVISÃO BIBLIOGRAFICA}

A armadilha de equilíbrio de baixo nível é um conceito em economia desenvolvido por Richard R. Nelson, no qual, em baixos níveis de renda per capita, as pessoas são pobres demais para economizar e investir, e esse baixo nível de investimento resulta em taxa de crescimento menor na economia e na renda nacional. Quando a renda per capita se eleva acima de um certo nível mínimo, uma proporção crescente da renda será economizada e investida, o que levará a uma maior taxa de crescimento da renda (NELSON, 1956).

Em conformidade com Nelson (1956) os problemas das economias subdesenvolvidas podem ser entendidos como um nível de equilíbrio constante da renda per capita ou próximo aos requisitos de subsistência. Nesse nível de equilíbrio estável baixo, a taxa de investimento e a poupança são baixas. Se a renda per capita for aumentada acima do nível mínimo de subsistência, isso incentivará o crescimento da população. Na opinião de Nelson, existem quatro condições que são propícias para armadilha de equilíbrio de baixo nível: 1) Uma alta correlação entre o nível de renda per capita e a taxa de crescimento populacional; 2) Baixa propensão a direcionar renda per capita adicional ao aumento do investimento per capita; 3) Escassez de terras aráveis não cultivadas e 4) Métodos de produção ineficientes.

RC: 94054

Disponível em: https://www.nucleodoconhecimento.com.br/ciencias-sociais/baixo- 
Vale destacar que essas hipóteses de Nelson foram pensadas para 1956, momento no qual não se observou a variável "tecnológica" (NELSON, 1956).

Segundo Nelson (1956), as principais causas do crescimento populacional na maioria dos países subdesenvolvidos nas últimas décadas têm sido a redução nas taxas de mortalidade devido a melhorias na saúde pública e no controle de epidemias e endemias, que não estavam intimamente relacionados ao aumento anterior do nível de renda per capita. Assim sendo, é primordial que os governos ofertem bens e serviços (saneamento básico) que possam contribuir para minimizar essas doenças provocadas por falta de infraestrutura básica.

Segundo Rohit Bura (1998) a teoria de Nelson (1956) possui pelo menos 02 (dois) problemas: Em primeiro lugar, a teoria pressupõe que um aumento na renda per capita até certo ponto leva a um aumento na taxa de crescimento da população por meio do declínio de morte. Mas o declínio na taxa de mortalidade em países subdesenvolvidos se deve mais a melhorias na saúde pública e nas instalações médicas do que ao aumento nos níveis de renda per capita. Em segundo lugar, a relação funcional entre o nível de renda per capita e a taxa de crescimento da renda total não é tão simples quanto se supõe na teoria (BURA, [s.d.], [1957?]).

Apesar das críticas, Richard R. Nelson publica em 1960, um estudo denominado "Growth Models and the Escape from the Low-Level Equilibrium Trap: The Case Of Japan" no qual os modelos de crescimento agregado são percebidos como ferramentas problemáticas para análise do crescimento econômico. Dessa foram, se o crescimento econômico for definido como um aumento da renda per capita, esses modelos não explicam o crescimento. Enquanto os parâmetros permanecerem fixos, eles impedem o crescimento. Pode-se deduzir uma taxa de equilíbrio de crescimento da renda nacional e um nível de equilíbrio da renda per capita. Embora esses modelos expliquem o crescimento da renda nacional total, o crescimento da renda per capita só pode ser explicado como movimentos em direção a um novo e maior equilíbrio resultante de mudanças nos parâmetros do modelo. Eles podem explicar

RC: 94054

Disponível em: https://www.nucleodoconhecimento.com.br/ciencias-sociais/baixo- 
uma "fuga da armadilha de equilíbrio de baixo nível, " e " o crescimento autossustentado" (NELSON, 1960).

Para Strand (2012), entende que a heterogeneidade dos serviços de utilidade pública é comum nos países em desenvolvimento. Em um equilíbrio de "alto nível", a qualidade dos serviços de utilidade (ex. saneamento) é alta, e com isso a disposição do consumidor em pagar pelos serviços é elevada, a concessionária é bem financiada e uma equipe bem paga para induzir um desempenho de alta qualidade. Em um equilíbrio de "baixo nível", o oposto acontece. Dessa forma, a qualidade da prestação dos serviços da concessionária e a percepção do público sobre a qualidade do serviço podem indicar a existência do Equilíbrio de Baixo Nível.

Segundo Strand (2012) o seu modelo se relacione com várias vertentes da literatura, todavia, nenhuma análise é satisfatória e diretamente comparável com múltiplos equilíbrios nos mercados de entrega de infraestrutura existente atualmente. Os mecanismos de "aprisionamento", nomeadamente um nível inadequado de fundos para libertar a economia da armadilha (em Nelson para investimento; aqui para recompensar a concessionária pelo esforço), são semelhantes no modelo Strand de 2012 e de Nelson de 1956. Outra vertente da literatura lida com centralização versus descentralização de serviços de utilidade pública. Estudos realizados em países da América Latina, para verificar a existência do equilíbrio de baixo nível, apresentaram, em maior ou menor grau, a presença de um modelo de gestão centralizado, gerando sistemas de provisão de água com características do EBN. Walker et al. (1999) verificaram tal circunstância em Honduras; Tamayo et al. (1999), no país Peruano; Ozuna e Gomez (1999), no modelo do México; Morandé e Doña (1999), nas companhias do Chile; e Artana; Navajas e Urbiztondo (1999), no caso da Argentina. Assim em conformidade com Spiller e Savedoff (1999) foi observado que os governos apresentam tendência para fixar preços abaixo do equilíbrio financeiro para o setor de abastecimento de água, provocando um desequilíbrio econômicofinanceiro para as empresas públicas e privadas que ofertam os serviços. Com a

RC: 94054

Disponível em: https://www.nucleodoconhecimento.com.br/ciencias-sociais/baixo- 
aplicação desse modelo, a redução na qualidade dos serviços e um baixo índice de cobertura são os resultados dessa política.

Ademais, com os preços baixos as empresas não realizam investimentos e a receita é comprometida para pagamento de salários, inviabilizando a expansão e a qualidade dos serviços. Quando o sistema é operado por empresa pública, os investimentos no setor ficam condicionados a repasses orçamentários do governo central (SPILLER; SAVEDOFF, 1999). Devido a essas políticas e à falta de credibilidade, as empresas privadas não efetivam investimentos no setor de fornecimento de água. As empresas privadas maximizam o lucro e minimizam os riscos. E caso existam empresas privadas no setor, a política de preços baixos, induz à redução de perdas, custos e investimentos necessários para a manutenção e o fornecimento dos serviços. Dessa forma, esse modelo provoca manutenção do setor com um Equilíbrio de Baixo Nível com pouca possibilidade de mudança (FARIAS; NOGUEIRA e MUELLER, 2005).

O Equilíbrio de Baixo Nível apresenta elevados custos sociais e merece prioridade na agenda do governo para não permanecer nesse modelo. Eles ainda observam que a falta do suporte político faz com que os governos mantenham os preços baixos (FARIAS; NOGUEIRA e MUELLER, 2005). Ao analisar essa opção dos governos de usar o EBN, Spiller e Savedoff (1999) questionam algumas das soluções por identificarem possíveis falhas. As principais falhas identificadas são: primeiro, o fato de que um aumento de preço, sem regras definidas, não é uma resposta eficiente; segundo, outra solução que não resulta em êxito é a implantação de um novo modelo de gestão nas operadoras públicas baseado em contratos de desempenho. Com esses contratos o governo estimula a operadora oferecendo uma parte do lucro incrementado pelo bom desempenho; uma terceira solução é promover contratos do tipo BOTs - Build, Operate and Transfer, que é uma forma de financiamento de projeto, em que uma entidade privada recebe uma concessão do setor público ou privado para financiar, projetar, construir, possuir e operar uma

RC: 94054

Disponível em: https://www.nucleodoconhecimento.com.br/ciencias-sociais/baixo- 
instalação declarada no contrato de concessão. Dessa forma, observa-se que as soluções propostas são insuficientes para mudar as Evidências do Equilíbrio de Baixo Nível (SPILLER; SAVEDOFF, 1999).

Para Spiller e Savedoff (1999, p. 20), o ideal seria ter um modelo no qual o poder discricionário do governo fosse limitado na determinação dos preços, sendo necessário que a empresa tivesse autonomia financeira e gerencial com base em três mecanismos demonstrados: i) restrições importantes devem estar incluídas de uma forma clara no contrato; ii) limitações sobre a possibilidade de alterações contrato; e iii) e que haja instituições de controle para acompanhar a execução do contrato.

Faria; Faria e Mota (2003) apresentam um estudo para entender a questão dos serviços de saneamento no Brasil, com bons indicadores de atendimento, se são sustentáveis a longo prazo. Para compreender esse tema, os autores usaram a Teoria do Equilíbrio de Baixo Nível (EBN) de Spiller e Savedoff (1999). Com base nessa teoria e com algumas condições iniciais que não limitem a intervenção política nas companhias de saneamento, gera-se um "oportunismo político" com preços abaixo dos custos dos serviços, provocando vários resultados indesejáveis e que repetem o ciclo vicioso de baixa desempenho dos serviços. De acordo com as hipóteses da EBN, as empresas com índices de atendimento adequado não estão isentas de apresentar indicadores de equilíbrio de baixo nível. Nesse sentido Faria; Nogueira e Mueller (2005) realizaram um estudo de caso da Companhia de Saneamento Básico do Distrito Federal.

Considerando as hipóteses da Teoria do Equilíbrio de Baixo Nível, o estudo pode ser refletido para outras empresas que trabalhem de maneira institucionalmente semelhante com a ausência de apoio político direta ou indiretamente. No primeiro caso, o governo não realiza ou retarda o equilíbrio econômico-financeiro, reduzindo o fluxo de caixa da companhia, provocando realocação de recursos públicos para a manutenção dos serviços. No segundo caso, os reajustes ocorrem, porém com

RC: 94054

Disponível em: https://www.nucleodoconhecimento.com.br/ciencias-sociais/baixo- 
ausência de apoio político direto, as manifestações contrárias ocorrem e geram uma deterioração do capital político muito representativo (FARIA; FARIA; MOTA, 2003).

Corroborando com a Teoria do Equilíbrio de Baixo Nível, Faria, Nogueira e Mueller (2005), apresentam um artigo examinando a EBN no seguimento de saneamento urbano brasileiro, conforme o modelo de Spiller e Savedoff (1999). Com base na EBN e suas premissas de viés de oportunismo do governo, constata-se o uso de preços abaixo dos custos de produção dos serviços, a deficiência de investimentos e a precariedade dos serviços disponibilizados à sociedade. Os resultados apresentados demonstram a existência de Equilíbrio de Baixo Nível, para o Brasil a exemplo de países da América Latina, para a qualidade dos serviços de abastecimento urbano de água e de esgotamento sanitário.

\section{MÉTODOS}

A metodologia adotada foi a pesquisa bibliográfica de caráter exploratório por meio do enfoque meta-analítico. O enfoque meta analítico utiliza o critério de impacto de revistas e artigos para a escolha do material a ser utilizado. Tem como objetivo combinar bases de dados conceituadas, para dessa forma apresentar um aporte de material válido. O enfoque meta-analítico possibilita obter os melhores autores, artigos e revistas, e realizar uma análise das técnicas estatísticas, das amostras, das linhas mais pesquisadas e das abordagens utilizadas (MARIANO; GARCIA CRUZ; ARENAS GAITAN, 2011).

De acordo com Ramirez Correa e Garcia Cruz (2005), o enfoque meta-analítico pode ser realizado em 4 etapas: 1) Determinação de artigos base para estudo; 2) Leitura de artigos, exclusão e inclusão de estudos; 3) Construção da base de dados e 4) Análises e exposição dos resultados. Por outro lado, Mariano; Garcia Cruz e Arenas Gaitan (2011), entendem que o estudo pode ser ampliado em até 7 etapas. Nesse trabalho, adotaram-se as 7 etapas descritas conforme a seguir: 1) Análise e apresentação das revistas da disciplina, e reconhecer as revistas mais utilizadas no

RC: 94054

Disponível em: https://www.nucleodoconhecimento.com.br/ciencias-sociais/baixo- 
contexto estudado; 2) Selecionar as revistas significativas do tema, utilizando com critério o fator de impacto ISI, que é calculado somando as citações dos artigos recebidas no ano do cálculo do fator de impacto e dividindo esse número pela quantidade de artigos publicados nos dois anos antecedentes a esse cálculo, Institute for Scientific Information (1998) apud Calazans; Masson e Mariano (2015), e quantidade de citações segundo SClamo Journal \& Country; 3) Coleta de dados para alimentação da base de dados - consiste no filtro, as palavras-chave do tema e as publicações escolhidas anteriormente; 4) Análise dos autores e artigos Compreende o cálculo da média anual de artigos sobre o tema pesquisado, e suas citações. Identificando os autores que mais publicaram sobre o tema; 5) Determinação dos Enfoques Teóricos de Pesquisa - trata de identificar os principais enfoques teóricos acerca do tema; 6) Análise das Palavras-Chave - propicia importantes subsídios a respeito do desenvolvimento do tema em questão e das linhas de pesquisa e 7) Estudo das relações dos artigos selecionados anteriormente.

\section{ANÁLISE E APRESENTAÇÃO}

Conforme apresentado antes, passaremos a demonstrar as etapas do trabalho com o enfoque meta-analítico.

\section{Etapa 1 - Análise e apresentação das revistas da disciplina}

Esse estudo foi desenvolvido usando as bases de dados da plataforma ISI Web of Science (WoS) no período de 1945 a 2020, com acesso no dia 30/11/2020, utilizando o descritor "low level equilibrium" (Equilíbrio de Baixo Nível), com base nas 452 revistas da principal coleção da plataforma WoS. Segundo Garcia; Ramirez, (2004) apud Calazans; Paldês e Mariano, (2015) a ISI Web of Science é designada mundialmente como uma das mais excelentes e completas bases de dados do mundo (INSTITUTE FOR SCIENTIFIC INFORMATION, 1998) apud (MARIANO; GARCIA CRUZ; ARENAS GAITAN, op. cit.). O estudo pesquisou as revistas relacionadas aos principais congressos e encontros relacionados ao tema da

RC: 94054

Disponível em: https://www.nucleodoconhecimento.com.br/ciencias-sociais/baixo- 
palavra-chave da pesquisa. A base do ISI Journal Citation Report Edition apresentou 452 revistas, considerando o domínio relacionado ao tema.

\section{Etapa 2 - Seleção de revistas relevantes da disciplina}

As revistas foram selecionadas segundo o fator de impacto ISI (Institute for Scientific Information). Dessa base, foram selecionadas as revistas com maior fator de impacto apresentadas na tabela 1.

Tabela 1. Revistas com maior fator de impacto (acima de 5.0)

\begin{tabular}{|l|l|}
\hline Revista & $\begin{array}{l}\text { Fator de } \\
\text { Impacto }\end{array}$ \\
\hline ENERGY \& ENVIRONMENTAL SCIENCE & 30.289 \\
\hline NATURE CLIMATE CHANGE & 20.893 \\
\hline NATURE SUSTAINABILITY & 12.080 \\
\hline GLOBAL ENVIRONMENTAL CHANGE-HUMAN AND POLICY & 10.466 \\
\hline DIMENSIONS & \\
\hline FRONTIERS IN ECOLOGY AND THE ENVIRONMENT & 9.295 \\
\hline WATER RESEARCH & 9.130 \\
\hline REMOTE SENSING OF ENVIRONMENT & 9.085 \\
\hline JOURNAL OF HAZARDOUS MATERIALS & 9.038 \\
\hline ENERGY POLICY & 5.042 \\
\hline APPLIED CATALYSIS A-GENERAL & 5.006 \\
\hline
\end{tabular}

Fonte: Web of Science (2020) - Elaboração própria

Etapa 3 - Coleta de dados para alimentação da base de dados

Identificadas as revistas com maior fator de impacto e/ou citações, foi realizada a busca "low level equilibrium" (Equilíbrio de Baixo Nível) no espaço temporal de setenta e cinco anos (1945-2020). O resultado nas revistas consultadas foi de 34

RC: 94054

Disponível em: https://www.nucleodoconhecimento.com.br/ciencias-sociais/baixo- 
artigos na Web of Science sobre o tema. A tabela 2. Apresenta as Revistas que mais foram citadas sobre esse tema. Vale destacar que dos 34 artigos apenas 24 receberam 01(uma) ou mais citações.

Tabela 2. Revistas mais citadas (acima de 10)

Revistas

Citações

\begin{tabular}{|l|l|}
\hline AMERICAN ECONOMIC REVIEW & 184 \\
\hline BRITISH JOURNAL OF POLITICAL SCIENCE & 141 \\
\hline JOURNAL OF ECONOMIC GROWTH & 104 \\
\hline INTEGRATIVE AND COMPARATIVE BIOLOGY & 94 \\
\hline $\begin{array}{l}\text { ARCHIVES OF ENVIRONMENTAL CONTAMINATION AND } \\
\text { TOXICOLOGY }\end{array}$ & 76 \\
\hline WATER RESOURCES RESEARCH & 40 \\
\hline SOIL \& TILLAGE RESEARCH & 28 \\
\hline JOURNAL OF MACROECONOMICS & 11 \\
\hline EUROPEAN ECONOMIC REVIEW & 10 \\
\hline
\end{tabular}

Fonte: Web of Science (2020) - Elaboração própria

Com relação ao quantitativo de publicação e citações, por ano, referente ao tema, observamos que o primeiro registro foi no ano de 1956 e 1960, com uma lacuna sem publicações e citações até o ano de 2003. No entanto, foi possível encontrar literatura sobre o tema "low level equilibrium" (Equilíbrio de Baixo Nível), nos anos de 1999, 2003, 2004 e 2005.

\section{Etapa 4 - Análise dos autores e artigos}

Os autores, que possuem artigos mais citados, estão apresentados na Tabela 3. É possível inferir dessa informação que, ao longo do período de 1945 a 2020, ocorreu

RC: 94054

Disponível em: https://www.nucleodoconhecimento.com.br/ciencias-sociais/baixo- 
uma oscilação quanto ao quantitativo de autores vs citações, não sendo possível projetar uma tendência, quanto ao tema.

Tabela 3. Autores com artigos mais citados/ano

\begin{tabular}{|c|c|c|c|}
\hline Artigos & Autores & Citações & Ano \\
\hline A THEORY OF THE LOW-LEVEL & NELSON, RR & 184 & 1956 \\
\hline $\begin{array}{lcl}\text { EQUILIBRIUM } & \text { TRAP } & \text { IN } \\
\text { UNDERDEVELOPED ECONOMIES } & \end{array}$ & & & \\
\hline $\begin{array}{l}\text { DEMOCRATIZATION } \text { BACKWARDS: THE } \\
\text { PROBLEM } \text { OF } \\
\text { DEMOCRACIES }\end{array}$ & $\begin{array}{l}\text { ROSE, R; SHIN, } \\
\text { DC }\end{array}$ & 141 & 2001 \\
\hline $\begin{array}{l}\text { CONTINUOUS SURVEILLANCE } \\
\text { ORGANOCHLORINE COMPOUNDS } \\
\text { HUMAN BREAST MILK FROM } 1972 \text { TO } \\
\text { 1998 IN OSAKA, JAPAN }\end{array}$ & $\begin{array}{ll}\text { KONISHI, } & \text { Y; } \\
\text { KUWABARA, } & \text { K; } \\
\text { HORI, S } & \end{array}$ & 76 & 2001 \\
\hline
\end{tabular}

Fonte: Web of Science (2020) - Elaboração própria

No Gráfico 1, podemos observar que de 1956 a 2009, ocorreram várias oscilações, quanto a citações referente ao tema. Já em 2010, notamos a tendência de declínio nos números de citações que tratam de palavras-chave "low level equilibrium" (Equilíbrio de Baixo Nível), em todo o período estudado foram contabilizados 741 citações.

RC: 94054

Disponível em: https://www.nucleodoconhecimento.com.br/ciencias-sociais/baixo- 
Gráfico 1. Citações vs Anos referente ao tema

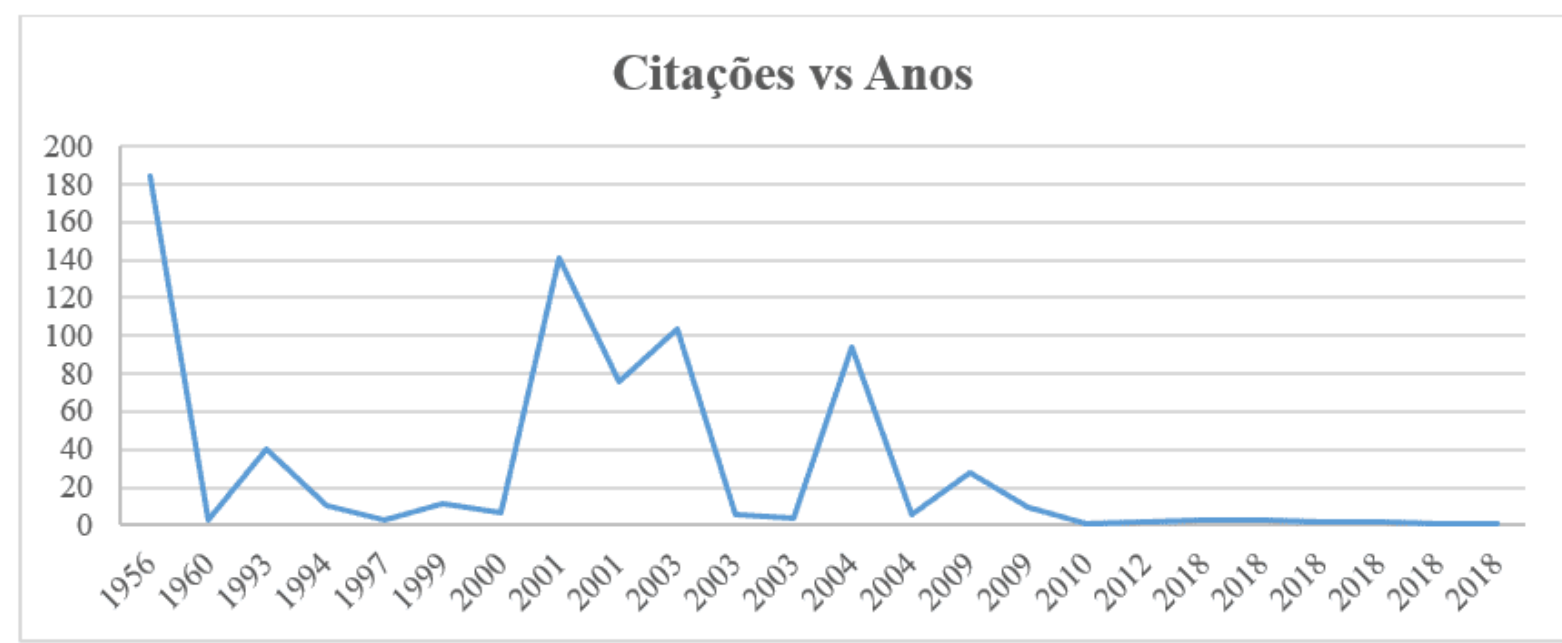

Fonte: Web of Science (2020) - Elaboração propria.

Ao todo, os artigos do período receberam 697 citações, do total de 741 citações de toda a base da Web of Science. Isso corresponde a $94,46 \%$ das citações. Dos 10 autores, só 1 autor produziu no período selecionado dois artigos. Esses dados permitem concluir que todos esses autores têm um significativo fator de impacto na literatura sobre "low level equilibrium" (Equilíbrio de Baixo Nível).

\section{Etapa 5 - Determinar Linhas e Enfoques Teóricos de Pesquisa.}

$\mathrm{Na}$ Tabela 4, apresentamos as principais linhas de pesquisa e enfoques que trataram do tema "low level equilibrium" (Equilíbrio de Baixo Nível). As linhas de pesquisa que mais trataram do estudo proposto foram: business economics (13 citações) e environmental sciences ecology responsáveis por 7 citações, representado $58,82 \%$ do total das linhas de pesquisa.

Tabela 4. Linhas de pesquisas

\begin{tabular}{l|l|l}
\hline Linhas de pesquisa & Registros & $\%$ of 34 \\
\hline BUSINESS ECONOMICS & 13 & 38.235
\end{tabular}

RC: 94054

Disponível em: https://www.nucleodoconhecimento.com.br/ciencias-sociais/baixo$\underline{\text { nivel }}$ 


\begin{tabular}{|l|l|l|}
\hline $\begin{array}{l}\text { ENVIRONMENTAL SCIENCES } \\
\text { ECOLOGY }\end{array}$ & 7 & 20.588 \\
\hline DEVELOPMENT STUDIES & 4 & 11.765 \\
\hline TOXICOLOGY & 3 & 8.824 \\
\hline WATER RESOURCES & 2 & 5.882 \\
\hline
\end{tabular}

Fonte: Web of Science (2020) - Elaboração própria

\section{Etapa 6 -Análise das Palavras-Chave.}

Com a finalidade de saber o rumo das novas pesquisas, foram usados critérios objetivos através de uma busca das palavras-chave. Essas palavras revelam características próprias de cada trabalho, permitindo agrupar os estudos e classificálos. O Gráfico 2 apresenta as 15 palavras-chave que obtiveram mais citações.

Gráfico 2. Palavras-Chave vs Citações

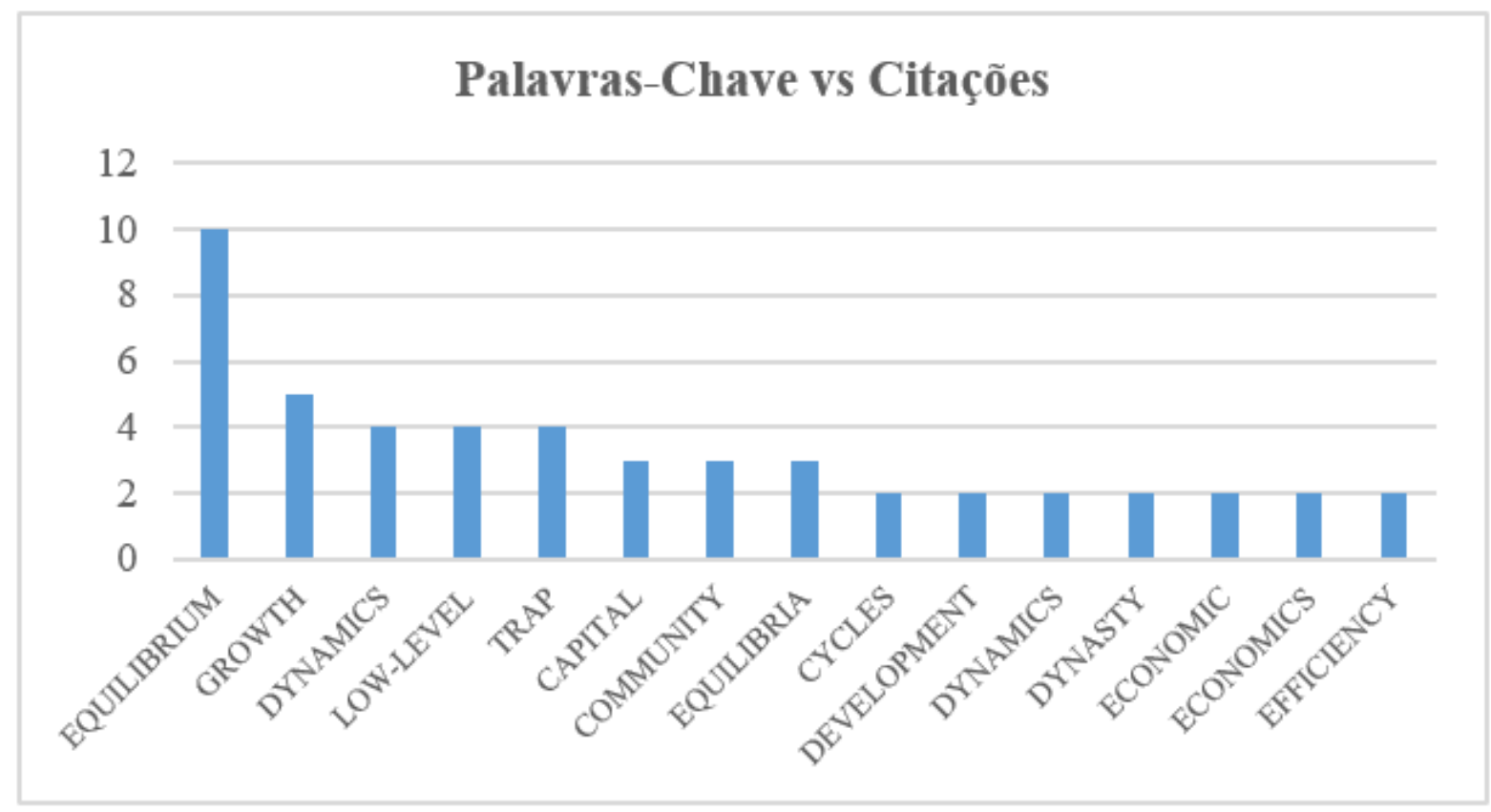

Fonte: Web of Science (2020) - Elaboração propria.

RC: 94054

Disponível em: https://www.nucleodoconhecimento.com.br/ciencias-sociais/baixo$\underline{\text { nivel }}$ 


\section{Etapa 7: Estudo das Relações.}

É importante investigar quais os enfoques que mais foram abordados, em que locais se têm aplicado as pesquisas (meio acadêmico ou indústria), qual a amostra, entre outras informações. A análise foi realizada considerando todos os 17 autores que abordaram o tema com seus artigos. A Tabela 5 apresenta parte da análise considerando os autores mais citados no período de 1956 a 2020.

Tabela 5. Linhas de pesquisas

\begin{tabular}{|c|c|c|}
\hline Autores & Artigos/ano & Enfoque \\
\hline $\begin{array}{l}\text { NELSON, } \\
\text { RR }\end{array}$ & $\begin{array}{l}\text { A theory of the low-level } \\
\text { equilibrium trap in } \\
\text { underdeveloped } \\
\text { economies/1956 }\end{array}$ & $\begin{array}{l}\text { O estudo avalia os problemas das } \\
\text { economias subdesenvolvidas que podem } \\
\text { ser entendidos como um nível de equilíbrio } \\
\text { constante da renda per capita ou próximo } \\
\text { aos requisitos de subsistência. Nesse nível } \\
\text { de equilíbrio estável baixo, a taxa de } \\
\text { investimento e a poupança são baixas }\end{array}$ \\
\hline $\begin{array}{l}\text { Rose, R; } \\
\text { Shin, DC }\end{array}$ & $\begin{array}{l}\text { Democratization } \\
\text { backwards: The problem } \\
\text { of third-wave } \\
\text { democracies/2001 }\end{array}$ & $\begin{array}{l}\text { Os países da terceira onda de } \\
\text { democratização introduziram eleições } \\
\text { competitivas antes de estabelecer } \\
\text { instituições básicas de um Estado } \\
\text { moderno, como o Estado de Direito, as } \\
\text { instituições da sociedade civil e a } \\
\text { responsabilidade dos governadores. Em } \\
\text { contraste, os países da primeira onda de } \\
\text { democratização tornaram-se Estados } \\
\text { modernos antes da introdução do sufrágio } \\
\text { universal. Por terem se democratizado ao } \\
\text { contrário desses, a maioria dos países da }\end{array}$ \\
\hline
\end{tabular}

RC: 94054

Disponível em: https://www.nucleodoconhecimento.com.br/ciencias-sociais/baixo- 


\begin{tabular}{|c|c|c|}
\hline & & $\begin{array}{l}\text { terceira onda são democracias } \\
\text { incompletas. As democracias incompletas } \\
\text { podem se desenvolver de três maneiras } \\
\text { diferentes: podem completar a } \\
\text { democratização; repudiar eleições livres e } \\
\text { se voltar para uma alternativa não } \\
\text { democrática; ou cair em uma armadilha de } \\
\text { equilíbrio de baixo nível em que as } \\
\text { inadequações das elites são } \\
\text { acompanhadas por baixas demandas e } \\
\text { expectativas populares. }\end{array}$ \\
\hline $\begin{array}{l}\text { Bloom, } \\
\text { DE; } \\
\text { Canning, } \\
\text { D; Sevilla, } \\
\text { J }\end{array}$ & $\begin{array}{l}\text { Geography and poverty } \\
\text { traps/2003 }\end{array}$ & $\begin{array}{l}\text { Testa a visão de que as grandes } \\
\text { diferenças nos níveis de renda que vemos } \\
\text { em todo o mundo são devidas a diferenças } \\
\text { na geografia intrínseca de cada país em } \\
\text { comparação com a visão alternativa de } \\
\text { que existem armadilhas da pobreza. } \\
\text { Rejeitando o determinismo geográfico } \\
\text { simples em favor de um modelo de } \\
\text { armadilha da pobreza com equilíbrios de } \\
\text { alto e baixo nível. O estado de equilíbrio de } \\
\text { alto nível é considerado o mesmo para } \\
\text { todos os países, enquanto a renda no } \\
\text { equilíbrio de baixo nível e a probabilidade } \\
\text { de estar no equilíbrio de alto nível são } \\
\text { maiores em países frios e costeiros. }\end{array}$ \\
\hline
\end{tabular}

Fonte: Web of Science (2020) - Elaboração própria

RC: 94054

Disponível em: https://www.nucleodoconhecimento.com.br/ciencias-sociais/baixo- 
Constatou-se no trabalho de NELSON, RR (1956) que os problemas do subdesenvolvimento de certas economias em um nível de equilíbrio constante da renda per capita ou próximo aos requisitos de subsistência, haja vista que no nível de equilíbrio estável, a taxa de investimento e a poupança são baixas. Com isso, inferimos com base na tabela 5 , que vários autores abordam o tema, equilíbrio de baixo nível, porém em outras áreas de conhecimento.

\section{CONSIDERAÇÕES FINAIS}

A finalidade do estudo foi avaliar a evolução das publicações sobre o tema "Equilíbrio de Baixo Nível" no período de 1945 a 2020, utilizando a abordagem metaanalítico. A metodologia da pesquisa foi a bibliográfica de especificidade exploratório, efetivando uma revisão com o enfoque meta-analítico. Foram empregados os sete passos desse método e, inicialmente, identificamos e selecionamos as revistas de maior fator de impacto do domínio estudado. Os dados permitiram identificar que o crescimento do quantitativo de artigos sobre esse assunto apresenta várias oscilações no decorrer do período observado, com um sinal de declínio nas duas primeiras décadas do século XXI, demonstrando a importância da retomada do tema nas agendas de pesquisas e/ou a revisitação dos estudos já apresentados para um melhor entendimento, questionamento e contribuições substantivas para o estado as artes.

Com relação aos autores e artigos, verificou-se o interesse de 7 (sete) países com relação ao tema proposto. A determinação dos enfoques e a análise das palavraschave e relacionamentos permitiram inferir que alguns artigos apresentam o tema Equilíbrio de Baixo Nível em outros campos de pesquisas (saúde, agricultura, mercado de trabalho, química e outros). Foi possível identificar que a maior parte dos artigos citados realiza avaliação empírica ou estudo experimental com relação ao tema.

RC: 94054

Disponível em: https://www.nucleodoconhecimento.com.br/ciencias-sociais/baixo- 
Aplicando as sete fases do enfoque meta-analítico, foi possível identificar os artigos dos autores mais citados nas revistas com maior fator de impacto, que acompanham as tendências dos estudos sobre um tema em decrescimento. Dessa forma, o presente tema é muito sugestivo para trabalhos futuros, e a sua retomada nas agendas de pesquisas poderá fortalecer o debate, e aprimorar em novos estudos e/ou revisitação e aplicação da teoria na área de políticas públicas.

\section{REFERÊNCIAS}

ARTANA, Daniel; NAVAJAS, Fernando; URBIZTONDO, Santiago. Governance and regulation: a tale of two concessions in Argentina. Spilled water: institutional commitment in the provision of water services. Washington, D. C.: InterAmerican Development Bank, 1999. Disponível em: $<$ https://citeseerx.ist.psu.edu/viewdoc/download?doi=10.1.1.690.1406\&rep=rep1\&typ e=pdf $>$ Acesso em: 19 fev. 2021.

BURA, Rohit. What is the Low Level Equilibrium Trap theory put forward by R.R. Nelson?. PreserveArticles.com. [s.d.], [1957?]. Disponível em: $<$ https://www.preservearticles.com/education/what-is-the-low-level-equilibrium-traptheory-put-forward-by-rr-nelson/28553>. Acesso em: 03 dez. 2020.

CALAZANS, Angelica Toufano Seidel; MASSON, Eloisa Toufano Seidel; MARIANO, Ari Melo. Uma revisão sistemática da bibliografia sobre inovação bancária utilizando o enfoque meta-analítico. Revista ESPACIOS. Vol. 36 (No 15) Año 2015.

<https://www.researchgate.net/publication/280831999_Uma_revisao_sistematica_da _bibliografia_sobre_inovacao_bancaria_utilizando_o_enfoque_metaanalitico_A_systematic_review_of_the_literature_on_banking_innovation_using_meta-analytic_approach>. Acesso em: 21 dez. 2020.

RC: 94054

Disponível em: https://www.nucleodoconhecimento.com.br/ciencias-sociais/baixo- 
CALAZANS, Angelica Toufano Seidel; PALDÊS, Roberto Avila; MARIANO, Ari Melo. Uma revisão sistemática da bibliografia sobre métricas funcionais de tamanho de software utilizando o enfoque meta-analítico. Universitas Gestão e TI, Brasília, v. $5, \quad$ n. 2 , p. 67-77, jul./dez. 2015. Disponível em: $<$ https://www.publicacoesacademicas.uniceub.br/gti/article/view/3532/2857>. Acesso em: 21 dez. 2020.

FARIA, Ricardo Coelho; NOGUEIRA, Jorge Madeira; MUELLER, Bernado. Políticas de Precificação do Setor de Saneamento Urbano no Brasil: As Evidências do Equilíbrio de Baixo Nível. Est. Econ., São Paulo, v. 35, n. 3, julho-setembro 2005. Disponível em: <http://dx.doi.org/10.1590/S0101-41612005000300004>. Acesso em: 19 fev. 2021.

FARIA, Ricardo Coelho; NOGUEIRA, Jorge Madeira. Método de Precificação da Água e Uma Análise dos Mananciais Hídricos do Parque Nacional de Brasília. Revista Econômica do Nordeste, Fortaleza, v. 35, no 2, abr.-jun. 2004. Disponível em:

<https://aprender.ead.unb.br/pluginfile.php/796346/mod_resource/content/1/M\%C3\% A9todo\%20de\%20precifica\%C3\%A7\%C3\%A30\%20da\%20\%C3\%A1 gua.pdf>. Acesso em: 19 fev. 2021.

FARIA, Simone Alves; FARIA, Ricardo Coelho de; MOTA, José Aroudo. A Instabilidade da Performance dos Serviços de Saneamento no Brasil. Planejamento e políticas públicas, n. 26, jun./dez, 2003. Disponível em: <http://repositorio.ipea.gov.br/bitstream/11058/4021/5/PPP_n26_Instabilidade.pdf>. Acesso em: 19 fev. 2021.

MARIANO, Ari Melo; GARCIA CRUZ, Rosário; ARENAS-GAITÁN, Jorge. Meta Análises como instrumento de pesquisa: uma revisão sistemática da bibliografia aplicada ao estudo das alianças estratégicas internacionais. Congresso internacional de Administração: Gestão Estratégica: inovação colaborativa e

RC: 94054

Disponível em: https://www.nucleodoconhecimento.com.br/ciencias-sociais/baixo- 
competitividade. 2011. Ponta Grossa Paraná: UEPG. Disponível em: <https://www.researchgate.net/publication/276410177_Meta_Analises_Como_Instru mento_de_Pesquisa_Uma_Revisao_Sistematica_da_Bibliografia_Aplicada_ao_Estu do_das_Aliancas_Estrategicas_Internacionais_Meta_Analysis_as_a_Tool_of_Resea rch_A_Systematic_Review_o> Acesso em: 19 fev. 2021.

MORANDÉ, Felipe; DOÑA, Juan E. Governance and regulation in Chile: fragmentation of the public water sector. Spilled water: Institucional commitment in the provision of water services. Washington, D. C.: Inter-American Development Bank, 1999.

Disponível

em:

$<$ https://publications.iadb.org/publications/english/document/Spilled-Water-

Institutional-Commitment-in-the-Provision-of-Water-Services.pdf> Acesso em: 19 fev. 2021.

NELSON, Richard R. A theory of low-level equilibrium trap in underdeveloped economies. American Economic Review. v. 46, p. 894-908, 1956. Disponível em: $<$ https://www.depfe.unam.mx/actividades/12/cursocrecimientoydesarrollo/02_nelson_1956.pdf> Acesso em: 19 fev. 2021.

NELSON, Richard R. Growth Models and the Escape from the Low-Level Equilibrium Trap: The Case of Japan. Economic Development and Cultural Change. v. 8, n. 4, p. 378-388. July/1960. Disponível em: <https://www.jstor.org/stable/1151720>. Acesso em: 19 fev. 2021.

RAMÍREZ CORREA, Patrício; GARCIA CRUZ, Rosario. Meta-análisis sobre la implantacion de sistemas de planificación de recursos empresariales (ERP). Journal of information systems and technology management. vol. 2, n. 3, p. 245-273, 2005. Disponível em: <https://www.scielo.br/pdf/jistm/v2n3/02.pdf> Acesso em: 19 fev. 2021.

RC: 94054

Disponível em: https://www.nucleodoconhecimento.com.br/ciencias-sociais/baixo- 
SAVEDOFF, William. D.; SPILLER, Pablo T. Government Opportunism and the Provision of Water. Spilled Water: Institutional Commitment in the Provision of Water Services. Inter-American Development Bank, 1999. 257 p. Disponível em: $<$ https://publications.iadb.org/publications/english/document/Spilled-WaterInstitutional-Commitment-in-the-Provision-of-Water-Services.pdf> Acesso em: 19 fev. 2021.

STRAND, Jon. Low-level versus high-level equilibrium in public utility services. The World Bank: Development Research Group: Environment and Energy Team. Washington DC, USA: Journal of Public Economics. v. 96, ํㅜ 1, 163-172, 2012. Disponível em: <https://openknowledge.worldbank.org/handle/10986/3487>. Acesso em: 19 fev. 2021.

TAMAYO, G. et al. Reform Efforts and low-level equilibrium in the peruvian water sector. Spilled water: institutional commitment in the provision of water services. Washington, D. C: Inter-American Development Bank, 1999. p. 89-134. Disponível em: <https://publications.iadb.org/publications/english/document/SpilledWater-Institutional-Commitment-in-the-Provision-of-Water-Services.pdf> Acesso em: 19 fev. 2021

WALKER, I. et al. Reform efforts and low- level equilibrium in the honduran water sector. Spilled Water: institutional commitment in the provision of water services. Washington, D. C: Inter American Development Bank, 1999. p. 35-88. Disponível em: <https://publications.iadb.org/publications/english/document/SpilledWater-Institutional-Commitment-in-the-Provision-of-Water-Services.pdf> Acesso em: 19 fev. 2021

Enviado: Julho, 2021.

Aprovado: Agosto, 2021.

RC: 94054

Disponível em: https://www.nucleodoconhecimento.com.br/ciencias-sociais/baixonivel 